\title{
Blazing the trail for robot-assisted cardiac surgery
}

Eric J. Lehr, MD, PhD

\author{
From the Swedish Heart and Vascular Institute, Seattle, Wash. \\ Disclosures: Author has nothing to disclose with regard to commercial support. \\ The article has been co-published with permission in The Annals of Thoracic Surgery and The Journal of Thoracic \\ and Cardiovascular Surgery. \\ Received for publication March 28, 2016; revisions received March 28, 2016; accepted for publication April 1, \\ 2016. \\ Address for reprints: Eric J. Lehr, MD, PhD, Swedish Heart and Vascular Institute, Jefferson Tower Cherry Hill, \\ 1600 E Jefferson St, Ste 110, Seattle, WA 98122 (E-mail: ericjlehr@gmail.com). \\ J Thorac Cardiovasc Surg 2016;152:14-7 \\ 0022-5223/\$36.00 \\ Copyright (C) 2016 by The Society of Thoracic Surgery \\ http://dx.doi.org/10.1016/j.jtcvs.2016.05.001
}

\begin{abstract}
Surgery of the heart has probably reached the limit set by nature to all surgery: no new method and no new discovery can overcome the natural difficulties that attend a wound of the heart.
\end{abstract}

$$
\text { -Stephen Paget, } 1896^{1}
$$

From the battlefield emerged the dream of remote telesurgery: The Defense Advanced Research Projects Agency funded a project to create a surgical drone that could be driven out into the front lines of war to perform operations on fallen soldiers. This dream, unrealized on the battlefield, became the foundation for the development of Intuitive Surgical's da Vinci (Sunnyvale, Calif) robotic platform, which promised to enhance complex technical operations in small spaces.

The da Vinci robot was launched clinically in 1998 for coronary and mitral valve operations. As with any new technology, there were early adopters, laggards, and naysayers. Many of the early adopters abandoned robotic operations, but others persisted, including several authors of the "Pathway for Surgeons and Programs to Establish and Maintain a Successful Robot-Assisted Adult Cardiac Surgery Program," published concurrently in this issue of The Annals and The Journal of Thoracic and Cardiovascular Surgery. ${ }^{2}$

Just as Paget predicted that operations could not be performed on the heart, so too opined Robicsek, ${ }^{3}$ Mohr, ${ }^{3}$ Elefteriades, ${ }^{4}$ and Damiano, ${ }^{5}$ each in the late 2000s, against "a widespread use of (robotics) in cardiac surgery in the future because most cases are really way too complex," even calling the robot "a million dollar coat hanger." 4

Since its debut, the da Vinci platform has been widely adopted in many surgical specialties, with 3597 units installed worldwide. ${ }^{6}$ It is now used in $85 \%$ of prostatectomies, with even greater use at high-volume centers. ${ }^{7}$ Despite its early foray into cardiac surgery, the penetration of robotic technology into our field has been primarily limited to a small number of highly specialized, high-

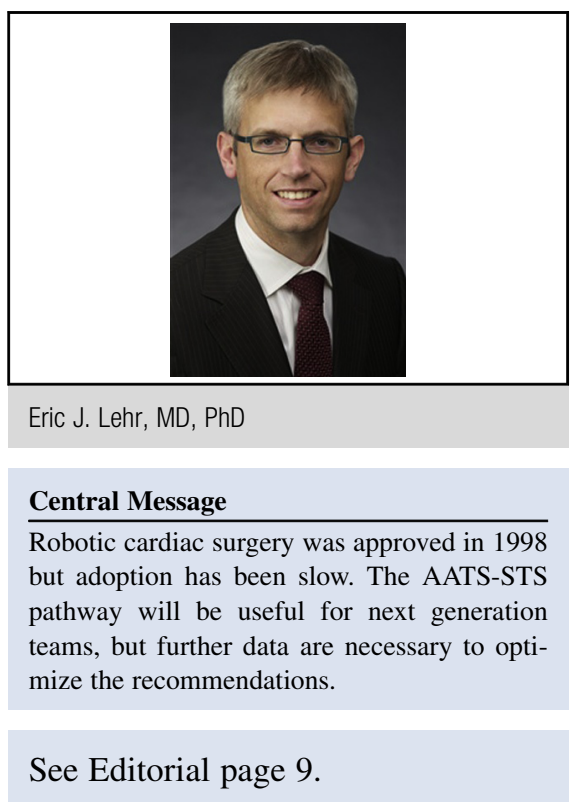

volume centers across the United States and the world. Programs where robotic cardiac surgery is firmly entrenched and frequently performed produce outstanding results that meet or exceed those for open operations in properly selected patient populations. ${ }^{8-10}$

An increasing variety of robotic cardiac operations beyond mitral valvuloplasty and surgical coronary revascularization have been reported in our literature, including hybrid coronary revascularization, transmyocardial laser revascularization, mitral valve repair for mitral stenosis, mitral valve replacement, tricuspid valve operations, repair of infective endocarditis lesions, aortic valve replacement, left ventricular-to-aortic valved conduit implantation, maze procedure for atrial fibrillation, atrioventricular node modification, left atrial appendage ligation, epicardial pacemaker lead implantation, resection of atrial myxoma, papillary fibroelastoma, and other cardiac tumors, septal myectomy, repair of congenital heart lesions not limited to ventricular septal defect, right ventricular outflow tract obstruction, and partial atrioventricular canal defects, as well as for cardiac trauma and adhesiolysis during reoperative cardiac operations. Concomitant robotic coronary artery bypass grafting and mitral valve repair has also been described. ${ }^{11}$ The spectrum of these reports demonstrates the breadth of procedures that are feasible by expert robotic cardiac surgeons.

W. Randolph Chitwood, Jr, one of the earliest pioneers in robotic cardiac surgery, has compared the development of minimally invasive mitral operations to climbing 
Mt. Everest with the robotic approach at the summit. Just as climbing Mt. Everest requires a dedicated team, an incredible amount of preparation and guidance, so too does the development of a robotic cardiac surgical program. The Web site of Alpine Ascents International, an Everest guide service, details the onerous requirements to summit Everest and provides benchmarks for physical conditioning, recommended experience, equipment lists, and training regimens. The application form demands the details of the prospective climber's experience level. ${ }^{12}$ Developing a robotic cardiac surgical program is no less daunting and requires equal commitment, perseverance, training, experience, and guidance.

Until now, a consensus statement informing the development of robotic cardiac surgical programs endorsed by The Society of Thoracic Surgeons or American Association for Thoracic Surgery has been lacking. On behalf of the Task Force on Robotic Surgery of The Society of Thoracic Surgeons/American Association for Thoracic Surgery Workforce on New Technology, Rodriguez and colleagues ${ }^{2}$ have published a long-awaited statement outlining a recommended pathway to guide hospitals in developing and maintaining a successful robot-assisted cardiac surgical program. This document is primarily a compilation of recommendations from some of the world's most experienced robotic cardiac surgeons.

In its decision memo for transcatheter aortic valve replacement, the Centers for Medicare and Medicaid Services mandated a number of requirements to participate as an implant center, perhaps most importantly the establishment of a cohesive and involved heart team. ${ }^{13}$ Similarly, requirements for success in developing a robotic cardiac surgical program extend far beyond the expertise of a skillful surgeon. Program success is highly dependent on a small stable team. Generally, a single surgeon, patient-side assistant, anesthesiologist, and perfusionist, as well as limited operating room personnel, cardiologists, and intensivists should be selected to concentrate the team's experience. Hospital administrators and nursing leaders need to be committed to the program. The team should have a foundation of depth and breadth with standard cardiac surgical cases.

With respect to the level of experience required to develop a successful robotic cardiac surgical program, the authors are intentionally vague, stating only that a "solid mitral valve surgical experience is absolutely necessary for a successful robotic-assisted mitral valve program" and that "the console surgeon should be facile in either sternotomy-based or minimally invasive coronary revascularization techniques." 2

But who or what defines a solid mitral valve experience or a facile coronary surgeon? It is well known that most of the cardiac surgical programs in the United States do not perform a high volume of mitral valve procedures. ${ }^{14}$
In mitral valve operations in the current era, expectations for repair are high: the 2014 American Heart Association/ American College of Cardiology Guideline for the Management of Patients With Valvular Heart Disease suggests that the likelihood of successful repair should exceed $95 \%$ for patients undergoing operations for severe asymptomatic mitral valve insufficiency with preserved left ventricular function. ${ }^{15}$ Bolling and colleagues ${ }^{16}$ reported in 2010 that the median number of mitral valve operations undertaken by surgeons performing mitral valve procedures was only 5 per year and that the median repair rate was only $41 \%$. They also demonstrated that the predicted probability and odds of mitral valve repair stabilize at an annual surgeon volume of 50 mitral cases. ${ }^{16}$

Their data are corroborated by a review of Washington State cardiac surgical outcomes that are publically reported by the Clinical Outcomes Assessment Program. At the time of this writing, 14 of the 18 hospitals performing cardiac operations in the Washington State were current in their reporting. Of the 14 reporting centers, only 2 performed more than 100 isolated valve procedures (includes both aortic and mitral), and just 6 centers performed more than 200 isolated coronary artery bypass grafting procedures in the past year.

The pathway encourages teams with adequate volume contemplating performing robotic cardiac operations to seek additional training and stresses that the training should include the entire team and not just the surgeon. Specific details, however, such as the number of procedures leading to competence, content of training courses, methods of training, procedural techniques, and the role for simulation are not discussed in the current document. Benefitting from standardized procedures, mature robotic surgical specialties have association-endorsed training modules. For example, the American Urological Society has developed online robotic surgery courses and white papers that enhance the understanding of indications, contraindications, methods, and the management of complications for robotic procedures. ${ }^{17}$

It is often stated that 20 cases is sufficient to gain competence for many different operative procedures. Bonatti and I have shown that the operative time for completing a robotic left internal mammary artery-to-left anterior descending artery graft falls dramatically after 20 cases, with further reductions observed as far out as 200 cases. Secondgeneration surgeons being mentored by expert robotic surgeons seem to progress faster along the learning curve than first-generation robotic surgeons. It is difficult to consider a robotic surgeon who has completed only 20 cases a master when the American Board of Thoracic Surgery requires new residents in the 6-year programs to complete a minimum of 500 cardiothoracic procedures ${ }^{18}$ during training. It would seem likely that a new robotic team learning new techniques for patient preparation, anesthesia, 
perfusion, and operative procedures with a complex device would need to perform far in excess of 20 procedures to achieve efficiency and outstanding results.

Simulation may have a role in accelerating the development and maintenance of robotic cardiac surgical skill sets. Valdis and colleagues ${ }^{19}$ recently reported faster acquisition of expert robotic internal thoracic artery harvesting and mitral annuloplasty skills with a high-fidelity wet laboratory simulator and that virtual reality simulation was a reasonable alternative to wet laboratory simulation.

Poston ${ }^{20}$ presented provocative data regarding the marketing of robotic cardiac surgical programs at the 2014 annual meeting of the International Society of Minimally Invasive Cardiac Surgery. He highlighted that robotic cardiac surgical programs often "[claimed] institutional superiority" even when their claims were "egregious and inaccurate." In addition, he noted that Web sites of " $47 \%$ of inactive [robotic] programs contain information about robotic cardiac surgery." ${ }^{20}$ The Task Force appropriately encourages surgeons and programs to be honest, transparent, and circumspect in their discussions with patients and in marketing with regards to the risks, benefits, and alternatives to the various surgical approaches to a patient's pathology.

A major limitation of the pathway is a lack of specific details and data-driven recommendations. Society guidelines from other surgical specialties provide deeper insight into training methods, learning curves, optimal procedure techniques, benefits of a robotic approach versus other minimally invasive procedures, patient outcomes, and required capital. Unfortunately, despite nearly 20 years of clinical experience, the cardiac surgical literature lacks sufficient data to answer these and other important questions. To receive payment for transcatheter aortic valve replacement, the Centers for Medicare and Medicaid Services mandated participation in a prospective national registry to monitor consecutive patients for 1 year and report major adverse events, quality of life, repeat procedures, and long-term outcomes. Robotic cardiac surgeons have frequently discussed the need for a database on an informal basis. The weaknesses in the evidence supporting the pathway serve as a clarion call for robotic cardiac surgeons to establish a database to accurately document and report outcomes. Until randomized trials can be performed, reports from a comprehensive database would have immense benefits for hospitals, surgeons, payers, and most importantly, patients.

Previous editorialists have been correct so far in that robotic cardiac surgery would not become widespread. Indeed, it is probably appropriate that robotic cardiac operations be limited to high-volume centers where the return on investment can be realized and experience can be concentrated to optimize patient outcomes. It seems, however, unlikely at this point that the predictions of the demise of robotic cardiac surgery will come to fruition at experienced robotic cardiac surgical centers with excellent outcomes.

Moreover, new surgical robotic technology, perhaps better suited for cardiac operations is on the horizon. Intuitive Surgical has received United States Food and Drug Administration approval to market its da Vinci Sp single-port robotic surgical system. Other players are poised to enter the field of surgical robotics. Titan Medical's (Toronto, Ontario, Canada) interactive, snake-like multiarticulating instruments reinserted through a single incision may prove to be a better system for working in the chest and around the heart. Robotic surgeons are eager to see how quickly and what kind of robotic technology Google (Mountain View, Calif) and Johnson \& Johnson (New Brunswick, $\mathrm{NJ}$ ) with a combined market capitalization of more than $\$ 800$ billion will create.

Irrespective of whether robotic cardiac surgery persists in the long-term, the Task Force on Robotic Surgery of The Society of Thoracic Surgeons/American Association for Thoracic Surgery Workforce on New Technology should be commended for presenting a pathway to successfully and safely establish and maintain a robotic cardiac surgical program. As the next generation of cardiac surgeons adopts robotic technology, they will need to respond to the clarion call to deepen the evidence base for these guidelines.

\section{References}

1. Paget S. The surgery of the chest. Bristol: John Wright \& Co; 1896:121.

2. Rodriguez E, Nifong LW, Bonatti J, Casula R, Falk V, Folliguet TA, et al. Pathway for surgeons and programs to establish and maintain a successful robot-assisted adult cardiac surgery program. Ann Thorac Surg. 2016;152:9-13.

3. Robicsek F. Robotic cardiac surgery: time told! J Thorac Cardiovasc Surg. 2008; 135:243-6.

4. Elefteriades JA. Robot for coronary artery bypass grafting: a "million dollar coat hanger." Cardiology. 2009;114:56-8.

5. Damiano RJ. Robotics in cardiac surgery: the emperor's new clothes. J Thorac Cardiovasc Surg. 2007;134:559-61.

6. Intuitive Surgical. Investor FAQ. Available at: http://phx.corporate-ir.net/ phoenix.zhtml?c=122359\&p=irol-faq\#22324. Accessed March 27, 2016.

7. Oberlin DT, Flum AS, Lai JD, Meeks JJ. The effect of minimally invasive prostatectomy on practice patterns of American urologists. Urol Oncol Semin Orig Investig. 2016;34:255.e1-5.

8. Bonaros N, Schachner T, Lehr E, Kofler M, Wiedemann D, Hong P, et al. Five hundred cases of robotic totally endoscopic coronary artery bypass grafting: predictors of success and safety. Ann Thorac Surg. 2013;95:803-12.

9. Yanagawa F, Perez M, Bell T, Grim R, Martin J, Ahuja V. Critical outcomes in nonrobotic vs robotic-assisted cardiac surgery. JAMA Surg. 2015;150:771.

10. Murphy DA, Moss E, Binongo J, Miller JS, Macheers SK, Sarin EL, et al. The expanding role of endoscopic robotics in mitral valve surgery: 1257 consecutive procedures. Ann Thorac Surg. 2015;100:1675-81.

11. Maciolek KA, Krienbring DJ, Naum ES, Arnsdorf SE, Balkhy HH. Combined totally endoscopic robotic coronary bypass and mitral valve repair via rightsided ports. Innov Technol Tech Cardiothorac Vasc Surg. 2013;8:310-5.

12. Alpine Ascents International. Preparation for Mount Everest climbs. Available at: https://www.alpineascents.com/everest-train.asp. Accessed March 20, 2016.

13. Centers for Medicare and Medicaid Services. Decision memo for transcatheter aortic valve replacement (TAVR) (CAG-00430N). Available at: https://www.cms. gov/medicare-coverage-database/details/nca-decision-memo.aspx?NCAId=257 $\&$ ver $=4 \&$ NcaName $=$ Transcatheter + Aortic + Valve + Replacement $+($ TAVR $) \& b c=$ ACAAAAAAIAAA\&. Accessed March 20, 2016.

14. Clinical Outcomes Assessment Program (COAP). CV Surgery Reporting. Available at: http://www.coap.org/COAPPublicReporting/index2.html. Accessed March 20, 2016. 
15. Nishimura RA, Otto CM, Bonow RO, Carabello BA, Erwin JP III, Guyton RA, et al. 2014 AHA/ACC Guideline for the Management of Patients With Valvular Heart Disease: Executive Summary: a report of the American College of Cardiology/American Heart Association Task Force on Practice Guidelines. Circulation. 2014;129:2440-92.

16. Bolling SF, Li S, O'Brien SM, Brennan JM, Prager RL, Gammie JS. Predictors of mitral valve repair: clinical and surgeon factors. Ann Thorac Surg. 2010;90: 1904-12.

17. American Urological Association. Urologic robotic surgery course. Available at: https://www.auanet.org/education/modules/robotic-surgery/index.cfm. Accessed March 20, 2016
18. American Board of Thoracic Surgery. Operative requirements. Available at: https://www.abts.org/root/home/certification/operative-requirements.aspx. Accessed March 21, 2016.

19. Valdis M, Chu MWA, Schlachta C, Kiaii B. Evaluation of robotic cardiac surgery simulation training: a randomized controlled trial. J Thorac Cardiovasc Surg. 2016:151:1498-505.

20. Poston R. Marketing of low volume robotic cardiac surgery programs via the internet and public reporting avenues. Abstract D61. Presented at International Society for Minimally Invasive Cardiothoracic Surgery Annual Scientific Meeting; Boston, MA; May 28-31, 2014. Available at: http://meetings.ismics. org/abstracts/2014/D61.cgi. Accessed March 20, 2016. 